\title{
Information society and Greek society: Socio-cultural and political incompatibilities
}

\author{
Demosthenes Agrafiotis \\ Professor of Sociology, National School of Public Health \\ 196, Alexandras Avenue, Athens, 115 21, Greece \\ Tel.: + 3016466243 , Fax: + 3016466243 \\ Email:agraf@compulink.gr
}

\begin{abstract}
The term information society is being used in the field of techno-science as well as in politics, cultural studies, journalism, and public discussions; yet, a question arises: is the term pertinent from a scientific point of view or acceptable from the political and socio-cultural perspectives of all modern societies?

The question is not only academically interesting but also of immediate practical concern since the conceptual accuracy and the study of its social perception is indispensable for successful, collective, and organized action. From a societal point of view, the technologies of information and telecommunications embody in an exemplary way the cultural mega-process and political mega-changes of contemporary societies. While it is more and more accepted that the essence of the new technologies is not technological, the fate of new information technologies is connected with the future of many other institutions and the summoning of multiple sources. The establishment and composition of the above-mentioned expression, leads to the hypothesis that the term information society should be used with the utmost care, provided of course that its connotation is recognized. In the case of Greek society, certain conditions and circumstances are not yet present which can render the use of the term/expression information society rather dysfunctional.

The nature of the obstacles that do not permit the use of the expression information society in the Greek case is both socio-cultural and political. On the horizon of the next century, it is urgent to determine which of these obstacles can be removed and by which mechanisms and social actors. It is equally important to
\end{abstract}


determine which socio-cultural and political particularities of Greek society will permit different social actors or groups to elaborate their presence in a global world.

\section{INTRODUCTORY REMARKS}

Many themes/issues of collective life whose nature is compound and intricate are defined by a complex of words or by a theoretical expression: for instance the Aids epidemic is the plague of the century, the prospects for molecular biology and biotechnology are called the kingpin of the twenty-first century, the next millennium is the area of intense religiousness and international political and social upheavals are the end of history.

The above expressions have particularly the ambition to prove clever or inventive and essentially to explore the effectiveness of communication. On the other hand, they seem to take advantage of one aspect so strongly that the complex meaning of the phenomenon they refer to is somehow lost. Thus, although many expressions have been presented in the social context of debates and discourses [1] very few, of course, have succeeded in establishing themselves.

These phrases-expressions remain valid for a certain period only; they are used for communication between individuals and groups and sometimes they are established without previous inspection of their validity or origins. The organization of society as a whole has primarily become a pole of attraction for many denominations and rhetorical expressions. In this spectrum, the industrial society [2] (a sociological term) has also been redefined - named the society of progress, the mature society, the society of abundance, the society of organization etc. Meanwhile the post-industrial [2] society's definitions range from the society of image, the society of knowledge to the postmodern society [3], [4], and so on. Very recently, the complex of the information society is beginning to appear in various areas and places and is being used in a number of social debates and discourses (political, journalistic). In this context, the following questions could be expressed: Is the term information society scientifically pertinent or valid and culturally acceptable? Under what circumstances is its use justifiable? Does it actually lead to a new form of social structure? Under what conditions should its use become acceptable in the case of Greek society? To what degree is the information society considered a pole, an objective of the initiatives of social actors in Greece? How do social actors use, (de)construct or even manipulate the expression Information Society?

\section{THE PROBLEM OF PERTINENCE AND VALIDITY}

There are two ways, two routes to be followed in terms of analysis which can be applied in order to specify the interconnections between the elements of the binomial [information-technologies-communication] and [society]. The first would start from the social and cultural changes and upheavals of the years 2,000-2,010 $\mathrm{AD}$ and would continue by focusing on how these new social and cultural circumstances determine the development of technological systems and, more 
specifically, of the socio-communicative strategies and their demands in terms of technical solutions.

The second way would start from the potential and the limitations of every technological system and especially of information technology and telecommunications; it would consequently focus on how these technologies could affect the present and future demands, needs and desires for information and how these technologies could cause change in many levels of the economic and sociocultural systems. Bearing in mind that the questions explored at the end of the last paragraph have been expressed at a societal level, it is clear that the first way of analysis should be the one to follow. Thus, in order to set the socio-cultural trends of contemporary societies, there should be a comparative presentation of the basic data of the industrial/post-industrial societies according to the contexts outlined by A. Touraine [2], [4].

(i) The industrial societies have kept an eminent place for their major invention, industrial capital; interwoven with labour, it allows a part of the social product to return to the production areas and to change infinitely the conditions of labour. This homeostasis of industrial capital also functions, without a doubt, in the post-industrial societies, but the crucial variables are now the knowledge and information which provide adequate feedback to the production system, and open up new horizons with increasing speed in any action. The industrial societies are allowing new balances to grow, from systemic origins, while the post-industrial societies are allowing other kind of balances to grow: those stemming from the theory of catastrophe or chaos.

(ii) In the last two centuries the dominant production and consumption systems are cultivating a meager universality which is based mainly on the activation of natural resources with, as a target, the international market. The industrial societies are forming a flowing system that weaves its way through the globe; in it, natural resources, money, information, products, machines are circulating creating a time space that decreases in the name of speed and continuous expansion. Traditional societies were looking towards a horizon where geography played an important part, while in industrial societies this horizon became planetary and in the post-industrial societies became global.

(iii) Industrial societies are turning towards the production of machines, appliances, and products. Mass production and productivity along with the standardization of human needs, all add up to the establishment of the total market. In the post-industrial societies this sort of challenge is being transferred to the administration of the system, simply because there is not only the need for production but also for ensuring production by protecting natural resources, the environment, and the quality of life. In traditional societies, survival was the central issue; in the industrial society, it was the massive production of goods and, in post-industrial societies, it is the management of information and material and immaterial systems.

(iv) Compared to traditional or primitive societies, the industrial societies' main characteristic is the continuous diversity of policies and institutions. The systematic and analytical separation of the social continuum goes hand in hand with the abandonment of meta-social references. Society is not the outcome of the will of one super being or of a deity anymore, but of the action taken by social groups in the name of progress, development and of the 
conquest and the transcendence of all limits - real or imagined. Industrial society seeks unity by continuously negotiating and setting new policies and institutions, by opening up with no a priori guarantees. In post-industrial societies, progress dynamics are subsiding, but the search for the new sustainable or not, politically justifiable or not - is still a dominant cultural model.

(v) Industrial society can also be called a society of strong historicity (historicité) [2], because this society has the material infrastructure and the knowledge as well as the cultural standards to intervene in its own mode of existence. The post-industrial society is mainly turning towards its production and not its reproduction. In this mega-process, information is the most crucial constituent, it is the fuel for boosting this whole, collective, and organized action [5]. This aforementioned production of society, however, will become a cultural problem in the context of the post-industrial society since the great challenge will be the invention of an actual meaning representing the huge potential in the production of material and non-material goods [6], [7].

(vi) The new technologies of information and telecommunications will possess the following characteristics: a complex combination of logical schemes, automatization and machines that clearly imitate human intellectual functions or biological systems, globalization, the high production cost of innovation, a significant contribution to scientific and technological research and development in order to shape and diffuse them [8]. On these grounds, we are also allowed to use the term techno-science [7]. The new technologies of information and communication will have direct consequences in the shaping of institutions and organizations, in the division of labour (in $\mathrm{mental} / \mathrm{manual} / \mathrm{male} / \mathrm{female}$ etc.), the training of employees, the relations between groups of professionals, the distribution of power in terms of decision-making [8]. Perhaps, the most basic element is the fact that communication, the most fundamental function of the socio-cultural process according to $C$. Lévi-Strauss, will be supported by these technologically dependent functions. In this context, technology should be classified in the social sciences since it determines both meaning and social interactions: information technologies from a simple instrument tend to become language (langage) [1].

(vii) According to studies referring to the future, three scenarios are the most eligible for direct materialization [7]. The first is a two-gear Europe, a dual Europe: its main characteristics are uneven areas, social groups, sexes, the accumulation of environmental problems, and the dominance of economic rationalism. The second is Europe as a fortress (L'Europe forteresse) whose basic aim would be to ensure economic growth and the strict control of the flux of population. At the same time, Europe will try to enforce a new Marshall Plan for the nations of the former Soviet Union. The third is a Europe oriented mainly towards the control of inequalities, the search for new forms of mutual support, and the emergence of new shapes that will help us all to live close to nature. The most probable meta-scenario would be that of the co-existence of these three scenarios in different areas of the European continent. In this perspective, the technological systems of information will face the dilemma of the particularity or the universality, of the social control 
of information [9], [10], of the creation of an electronic illiteracy at a global level, and the possible emergence in power of information highways. Without any doubt, the presentation of these ideas concerning the cultural characteristics of contemporary societies has been positive and epic. Yet, in the societies of progress, the elements that are in contrast to these ideas coexist as negative consequences with unpredictable side effects; inevitable outcomes include the existence of uniformity in the uncontrollable abundance of society, the establishment of a technocratic elite, the transformation of nature into a repository of sources that calls for exploitation, the lack of participation in fundamental decisions for social evolution, the restriction of alternatives, the social and psychological cost that arises from the establishment of a fast pace of life with little or no time available, and the pursuit of constant changes [11], [12].

The process of pointing out the above-mentioned socio-cultural characteristics, although totally indicative and far from any sense of completion, allows some elements to be outlined in order to answer the questions that arose as far as the scientific pertinence of the term Information Society is concerned. Information will undoubtedly play an important role and checking its basis will be a turning point for the action taken by organizations, institutions, regions and nations [12], [14]. It is also clear that any sort of information requires a certain frame, a dynamic and a whole set of conditions and circumstances whose nature is neither technological nor scientific.

In this sense, the term information society refers to a crucial or prevailing element of modern societies without referring in an obligatory manner to the whole of the socio-cultural dynamic. It does not possess the pertinence to characterize or to predetermine what takes place in contemporary and future societies because the essence of information technology is not technological - as a lot of variables and situations of non-technological nature contributed to its production and consumption (see (i) - (vii) above). Since this expression is not valid enough to act as a denomination, it can be a source of connotations - and, for that matter, very rich ones. This fact leads us to the following wise form of attitude: in order for the term information society to be acceptable there should be convergent assumptions and conditions (examples of conditions are presented in (i)-(vii) above), otherwise there lies the risk of creating confusion and simplifications which in turn are completely opposed to the cultural norm of accurate diagnosis and subsequently of the denomination or specification of reality. That is to say, the expression information society loses its scientific pertinence, social validity and, finally, its cultural legitimacy.

\section{THE GREEK CASE}

Every society finds its characteristic mark in the intersection of the readings provided by history and sociology. According to this axiom, these readings are the contribution of cultural sociology and also the instrument for recognizing the special and specific characteristics of the industrial and post-industrial societies in the cultural history of mankind in relation, of course, to the challenge of the new 
technologies of information and communication. It is therefore essential that this assumption should be checked out and assessed in accordance with Greek society.

It could be said that Greek society is characterized by a continuous lack of correspondence between goals and means, and between orientations and mobilizing or organizing mechanisms, while it has introduced technologies, institutions, data and practices of the industrial society from the dawn of the century, industry changes from development to retrogression - an alternation of industrialization and de-industrialization; autonomous growth seems to be unapproachable. Besides, the co-existence of structures of pre-industrial, industrial and post-industrial characters is intensifying the presence of diversity and variety. The challenges that are directly connected with the application of information technologies imported into Greece will interweave this diverse world of economic and socio-cultural meanings.

In relation to other European societies the challenge for Greek society to direct its socio-cultural trajectory towards the information society is double:

(i) to overcome the socio-cultural deficiencies due to a rapid transformation of traditional Greek society (the dominant form until the Second World War) to industrial and even post-industrial society without having the time for political and cultural institutions to foster their status and role. These uncertainties create a situation of interventions coming too early or too late, an absence of reform cultures and, finally, a confusion between the objective and corresponding actions.

(ii) to define or at least to make visible the Greek version of the information society in a such a way that the actions of social actors can find a relative place in a global and coherent framework. A lot of actors have already implemented (partial) projects but the overall product is poor in synergies. The heterogeneity of socio-cultural conditions is accentuated by the heterogeneity of the initiatives. The information society oscillates between the two extremes: a) a strategic objective for innovative Greek enterprises in the global market; b) ideological, rhetorical devices or poles for apocalyptic (positive or negative) attitudes.

Until now, it is extremely difficult to distinguish the social actor who has the capacity to play the leading role in tracing the pathway towards the information society. The public sector is characterized by its pre-industrial inertia, the private sector has to face questions of scale and poor traditions of major social changes, the political system has not completed the phase of democratization and rationalization, and civil society is characterized by a mixture of over-fascination with the new and confidence that no major upheavals are probable.

Could the threat from the international scene (competitiveness, unemployment, lost autonomy, acculturation) play the role of catalyst? Or have the initiatives to be local and internal in spite of the pressure of planetary evolution?

This development will render the use of the term information society even more difficult and risky from a scientific point of view. In other words, in order to use the term information society (even in its most vaguely scientific version) in Greek society, it is not enough simply to introduce new information technology systems but to adopt and develop institutions and socio-cultural models thoroughly in conjunction with the social part of these systems. Furthermore, there should be an effort to understand and to face a number of future challenges in the 
interfaces of the whole: Information/Science-Technology/Economy/Society - not only in the Greek context but in European and in international perspectives.

These challenges are of different nature, for example:

a) Epistemological. How to avoid the contradiction related to the a priori use of term information society in different socio-cultural contexts? To what degree is this term pertinent, when it permits an investigation of different dimensions of reality or when it can predict its evolution [2], [4]?

b) Scientific. What kind of social research is needed to elucidate the mode of existence of the information society, its evolution, and its internal contradictions? To what degree can comparative studies contribute to this elucidation [15], [16]?

c) Semantic. Why has the term information society been elaborated recently in contemporary societies? What type of social imagery corresponds to it? What variety of meanings can it generate in different segments of the population? How do individuals construct or elaborate discourses and realities in the name of the information society [17], [20]?

It is clear that the ambiguity of the information society is not of a negative character. This ambiguity could be the origin for a fertile and polymorphous questioning. But, of course, the answers presuppose long-term action and research [16].

\section{CONCLUSION}

The introduction and use of a term or expression is a complicated procedure which is definitely not impartial to interests, conflicts, and challenges on a national, European or international level. Given the fact that there are ambiguities and multiple meanings in the expression information society, it is necessary to examine its articulations and its complications in order for this expression to become a starting point for analysis and action and not to produce a diagnosis of contradictory perspectives or rejection of alternative social initiatives. If, every time the subject comes up, it is implied that technology and science are the results of a socio-cultural evolution then, the expression information society does make sense; and if this expression encourages the multiple articulation of [Science-Technology] and [Society], then the cultural legitimation of its use is strongly reinforced. In the case of Greek society in order for information society to be accepted as a sociocultural horizon, a series of incompatibilities of a diverse nature have to be overcome. This means that a systematic and well conceived plan of action has to be implemented at a variety of levels in order to achieve coherence and a convergence of efforts. If this type of effort is not initiated, not implemented, not completed, it renders the use of the term-expression information society rather dysfunctional and socio-culturally unfounded. 


\section{REFERENCES}

1. D. Agrafiotis, Theoretical Aspects of the Complex: Art and New Technologies, in K. Brunnstein and E. Raubold (Ed.), IFIP, 13th World Congress 94, Volume 2, Elsevier Science, P.V., 1994, 714-15.

2. A. Touraine, La production de la société, Seuil, Paris, 1974.

3. A. Touraine, Critique de la Modernité, Fayard, Paris, 1992.

4. D. Agrafiotis, Politistikes idiotypies tis viomihanikis kinonias sto Viomhaniki Archaiologia Viomihanikos Politismos, EIE/Archaiologia (in press).

5. Epistimoniki Ekthesi, $H$ Epikinonia stin Evropi toy avrio. Pera apo tin technologia, Tomos 4, Programma FAST II, E.E.K., 7/1988.

6. V. Laopodis (Ed.), Communicators Across the Research - Society Interface, Proceedings of the 1st CORSI Meeting, Luxembourg, 19 and 20 May 1994, Interfaces, Science-TechnologySociety, E.C. - DGXIII, 1995.

7. D. Agrafiotis, Technologia - Systimata Ygias - Politismos, Koinoniogramma, No. 32, 12/1994.

8. Euroabstracts, Technology and Society: EU Initiatives in Technology Assessment, No. 33, January, 1995, 3-10.

9. V. Laopodis and D. Gritzalis, Information Services for Assessing the Impact of Technology in an Information Society (in press).

10. V. Laopodis and F. Fernandez, Enhancing Citizens Participation in an Information Society, 5th Hellenic Conference on Informatics, December 1995, published by the Greek Computer Society.

11. L'évolution des valeurs des Européens, Numéro spécial. Futuribles, No 200, 7-8/1995.

12. Report EPTA, Conference on Information Society, Rathenau Institute, The Hague, 1996.

13. Report, The Information Society, Policy Options for the New Telecommunications, STOA/European Parliament, Luxembourg, 1996.

14. Report, The Information Society, Information and Communication Technologies for Sustainable Technical Development, STOA/European Parliament, Luxembourg, 1996.

15. P. Ahonen, Strategies to Elaborate the Information Society: An EE - Finland Comparison, ESST: A laboratory without walls?, Athens, Greece, September 13-15, 1996.

16. J. Berleur, Information Highway Belgian Policy Confronted to Different European Utopias, ESST Third Working Conference, ESST: A laboratory without walls?, Athens, Greece, September 13-15, 1996.

17. J.F. Lyotard, La condition post-moderne, Minuit, 1979.

18. J.F. Lyotard, Les moralités post-modernes, Galilée, Paris, 1993.

19. F. Chatelet, J. Derrida, M. Foucault, J.F. Lyotard and M. Serres, Politiques de la philosophie, Figures/Grasset, Paris, 1976.

20. G. Fourez, Scientific and Technical Literacy in a Socio-Constructivist Perspective. Third Working Conference, ESST: A laboratory without walls? Athens, Greece, 13-15 September, 1996. 